\title{
Deep Breathing Improves End-Tidal Carbon Dioxide Monitoring of an Oxygen Nasal Cannula-Based Capnometry Device in Subjects Extubated After Abdominal Surgery
}

\author{
Shunsuke Takaki MD PhD, Kenji Mizutani MD, Moeka Fukuchi MD, Tasuku Yoshida MD, \\ Masahumi Idei MD, Yuko Matsuda MD, Yoshikazu Yamaguchi MD, Tetsuya Miyashita MD PhD, \\ Takeshi Nomura MD PhD, Osamu Yamaguchi MD PhD, and Takahisa Goto MD PhD
}

\begin{abstract}
BACKGROUND: Capnometry detects hypoventilation earlier than pulse oximetry while supplemental oxygen is being administered. We compared the end-tidal $\mathrm{CO}_{2}\left(\mathrm{P}_{\mathrm{ETCO}_{2}}\right)$ measured using a newly developed oxygen nasal cannula with a $\mathrm{CO}_{2}$-sampling port and the $\mathrm{P}_{\mathrm{aCO}}$ in extubated subjects after abdominal surgery. We also investigated whether the difference between $\mathbf{P}_{\mathrm{aCO}}$ and $\mathbf{P}_{\mathrm{ETCO}_{2}}$ is affected by resting, by spontaneous breathing with the mouth consciously closed, and by deep breathing with the mouth closed. METHODS: Adult post-abdominal surgery subjects admitted to the ICU were enrolled. After extubation, oxygen was supplied at $4 \mathrm{~L} / \mathrm{min}$ using a capnometrytype oxygen cannula. The breathing frequency, $\mathbf{P}_{\mathrm{ETCO}_{2}}$, and $\mathrm{P}_{\mathrm{aCO}}$ were measured after $30 \mathrm{~min}$ of oxygen supplementation. $P_{\mathrm{ETCO}_{2}}$ was continuously measured during rest, during breathing with the mouth consciously closed, and during deep breathing with the mouth closed. The difference between $\mathbf{P}_{\mathrm{ETCO}_{2}}$ and $\mathrm{P}_{\mathrm{aCO}}$ during various breathing patterns was analyzed using the Bland-Altman method. RESULTS: Twenty subjects were included. The bias \pm SD (limits of agreement) for breathing frequency measured by capnometry compared with those obtained by direct measurement was $0.4 \pm 3.6$ (-6.7 to 7.4). In $\mathrm{P}_{\mathrm{ETCO}_{2}}$ compared with $\mathrm{P}_{\mathrm{aCO}_{2}}$, the biases (limits of agreement) were $14.8 \pm 8.2(-1.3$ to 30.9$)$ at rest, $10.2 \pm 6.4(-2.3$ to 22.7$)$ with the mouth closed, and $7.7 \pm 5.6(-3.2$ to 18.6) for deep breathing with the mouth closed. $\mathrm{P}_{\mathrm{ETCO}_{2}}$ determined using the capnometry device yielded unreliable and widely ranging values under various breathing patterns. However, deep breathing with the mouth closed decreased the difference between $\mathbf{P}_{\mathrm{ETCO}_{2}}$ and $\mathbf{P}_{\mathrm{aCO}}$, as compared with other breathing patterns. CONCLUSIONS: $P_{\mathrm{ETCO}_{2}}$ measurements under deep breathing with mouth closed with a capnometry-type oxygen cannula improved the prediction of the absolute value of $\mathbf{P}_{\mathrm{aCO}_{2}}$ in extubated post-abdominal surgical subjects without respiratory dysfunction. Key words: $P_{\mathrm{aCO}}$; breathing frequency; capnometry; end-tidal carbon dioxide; monitoring. [Respir Care 2017;62(1):86-91. (C) 2017 Daedalus Enterprises]
\end{abstract}

\section{Introduction}

Respiratory depression secondary to the residual effects of anesthetics, muscle relaxants, and opioids is a wellrecognized hazard in the postoperative period. Therefore,

All authors are affiliated with the Intensive Care Unit, and Dr Miyashita is also affiliated with the Department of Anesthesiology, Yokohama City University, Yokohama, Kanagawa, Japan.

Drs Shunsuke Takaki and Kenji Mizutani contributed equally to this work as first authors. the practice guidelines published by the American Society of Anesthesiologists in 2002 recommended monitoring of Drs Takaki and Fukuchi presented a version of this paper at the annual congress
of Euroanaesthesia 2015, held May 30-June 2, 2015, in Berlin, Germany.

The authors have disclosed no conflicts of interest.

Correspondence: Shunsuke Takaki MD PhD, 3-9 Fukuura Kanazawaku Yokohama 236-0004, Kanagawa, Japan. E-mail: shunty5323@gmail.com.

DOI: $10.4187 /$ respcare.04634 
respiratory function during recovery for early detection of hypoxemia. ${ }^{1}$ Assessment of the airway patency, breathing frequency, and $\mathrm{S}_{\mathrm{pO}_{2}}$ during the postoperative recovery should be used. However, $\mathrm{CO}_{2}$ monitoring during spontaneous breathing was not clearly mentioned in the most recent guidelines updated in 2013. ${ }^{2}$

Hypoxia may be a late sign of hypoventilation while oxygen is being administered. Therefore, monitoring of the end-tidal carbon dioxide concentration $\left(\mathrm{P}_{\mathrm{ETCO}_{2}}\right)$ using capnometry may be more reliable than $\mathrm{S}_{\mathrm{pO}_{2}}$ in detecting hypoventilation. ${ }^{3}$ Capnography has been shown to be a more reliable predictor of hypoxemia than pulse oximetry. In sedated and postoperative patients receiving supplemental oxygen, capnography can detect hypoventilation faster and more reliably than pulse oximetry. ${ }^{4,5}$ Furthermore, Soto et $\mathrm{al}^{6}$ have reported that monitoring of nasal capnography is as reliable as plethysmography.

$\mathrm{P}_{\mathrm{ETCO}_{2}}$ monitoring is achieved using 2 methods (ie, mainstream and sidestream monitoring). In mainstream monitoring, $\mathrm{CO}_{2}$ is detected directly during a ventilation circuit. On the other hand, sidestream approaches continuously draw $\mathrm{CO}_{2}$ from the patient's airway to the monitor. Therefore, $\mathrm{CO}_{2}$ detection by sidestream monitoring is sometimes unstable, due to occlusion of the sampling tube and unstable breathing in non-ventilated patients. ${ }^{7}$ Several studies have reported that mainstream monitoring was superior to sidestream monitoring for detection of $\mathrm{P}_{\mathrm{ETCO}_{2}}$, in both ventilated and non-ventilated subjects. ${ }^{8-10}$ However, oral guidance could improve the performance of $\mathrm{P}_{\mathrm{ETCO}_{2}}$ detection by using a nasal canulla for sidestream capnometry. ${ }^{10}$ Therefore, alteration of the breathing pattern from mouth breathing to nose breathing may improve the performance of $\mathrm{P}_{\mathrm{ETCO}_{2}}$ detection and the difference between $\mathrm{P}_{\mathrm{ETCO}_{2}}$ and $\mathrm{P}_{\mathrm{aCO}}$.

In a previous study, we found that an oxygen maskbased capnometry device was useful for measuring $\mathrm{CO}_{2}$ postoperatively. ${ }^{11}$ In this study, deep breathing reduced dissociation between $\mathrm{P}_{\mathrm{ETCO}}$ and $\mathrm{P}_{\mathrm{aCO}}$. This newly developed capnometry-type nasal cannula (Japan Medical Next, Tokyo, Japan) has a unique sampling line inside the cannula for use in spontaneously breathing patients (Fig. 1). Each lumen of the cannula is divided into 2 parts, one part supplying oxygen and the other sampling air for the measurement of $\mathrm{P}_{\mathrm{ETCO}_{2}}$. However, one potential drawback of this nasal cannula is that $\mathrm{CO}_{2}$ may not be detectable if the patients breathe through their mouths. Healthy adults normally breathe through the nose, but during the postoperative period, congestion of the nasal mucosa and the use of a nasal drainage tube may impede air flow through the nose as compared with the mouth. These alterations may prompt the patient to switch from nasal to mouth breathing, and both pediatric and adult patients commonly mouthbreathe at rest. ${ }^{12}$

\section{QUICK LOOK}

\section{Current knowledge}

Monitoring of $\mathrm{S}_{\mathrm{pO}_{2}}$ is common practice during postoperative recovery. In the clinical situation, capnometry is an alternative method to pulse oximetry for the early detection of hypoventilation. Although there is a standard respiratory assessment, the appropriate means of monitoring spontaneous breathing remain undetermined.

\section{What this paper contributes to our knowledge}

Various respiratory monitoring devices were assessed, and the present device presented results similar to those in a previous study. The $\mathrm{P}_{\text {ETCO }}$ values and breathing frequency were too unstable to allow for the prediction of the absolute values using this capnometry-type nasal cannula. Hence, although direct measurement is the accepted standard for respiratory assessment, this continuous respiratory monitoring device may support postoperative care. Moreover, deep breathing with the mouth closed improved the prediction of $\mathrm{P}_{\mathrm{ETCO}}$ values using this capnometry-type nasal cannula.

In the present study, we compared the breathing frequency measured directly with that measured by capnometry using a nasal cannula with a $\mathrm{CO}_{2}$ sampling port (capnometry-type nasal cannula) in subjects extubated after abdominal surgery. We also compared the $\mathrm{P}_{\mathrm{ETCO}_{2}}$ and the pressure of carbon dioxide in the arterial blood $\left(\mathrm{P}_{\mathrm{aCO}_{2}}\right)$. A previous study already reported that mainstream and sidestream measurements with an oral guide device could measure $\mathrm{P}_{\mathrm{ETCO}_{2}}$ more accurately than a standard sidestream measurement. ${ }^{10}$ Therefore, in this study, we aimed not only to assess the accuracy of $\mathrm{P}_{\mathrm{ETCO}_{2}}$ monitoring using this device, but also to determine whether the breathing pattern affects $\mathrm{P}_{\mathrm{ETCO}_{2}}$ monitoring during post-anesthetic care. We investigated whether $\mathrm{P}_{\mathrm{aCO}_{2}}$ and $\mathrm{P}_{\mathrm{ETCO}}$ differed significantly during resting, during spontaneous breathing with the mouth consciously closed, and during spontaneous breathing through the nose with the mouth closed.

\section{Methods}

\section{Study Design}

The ethics committee of our hospital approved the study design, and the protocol is registered at the University Hospital Medical Information Network Center (UMIN000014062). Informed consent was obtained from all enrolled subjects. 


\section{Nasal Cannula-Based Capnometry in Extubated Subjects}

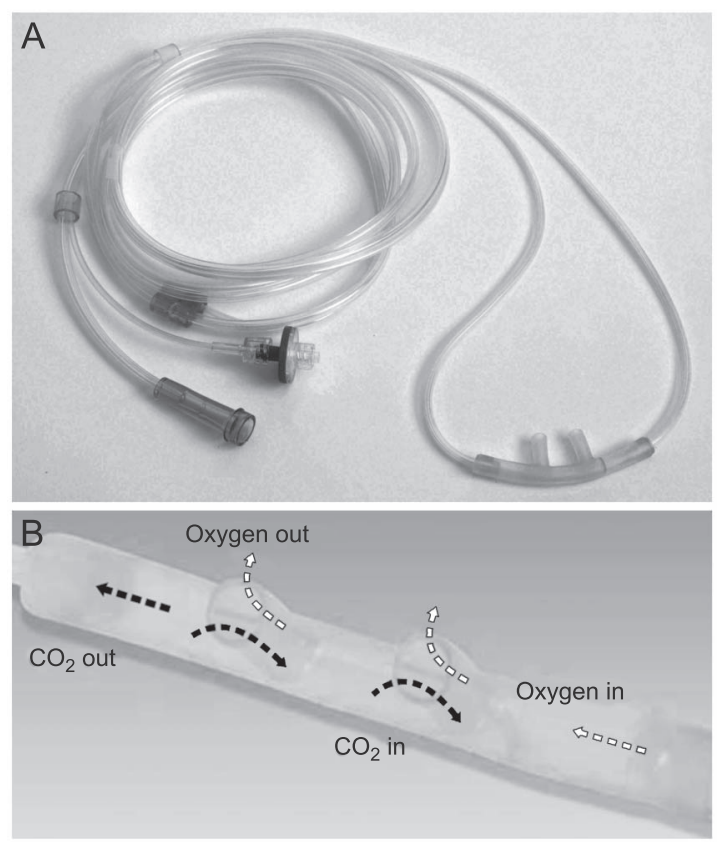

Fig. 1. Capnometry-type nasal cannula used in the study (A). The device has a unique sampling line inside the cannula for use in spontaneously breathing subjects. Each lumen is divided into 2 parts, one part supplying oxygen and the other measuring the end-tidal carbon dioxide concentration (B).

\section{Study Setting and Population}

The present study was conducted at a teaching hospital in Japan. Adult patients undergoing abdominal surgery and admitted to the ICU postoperatively were included. The nasogastric tube was removed before supplementation of oxygen by our oximetry device. Patients age $<18$ y, with an $\mathrm{S}_{\mathrm{pO}_{2}}$ of $<95 \%$ during oxygen supplementation at $4 \mathrm{~L} / \mathrm{min}$ delivered by a nasal cannula, who did not receive epidural anesthesia, who were obese (body mass index $>30 \mathrm{~kg} / \mathrm{m}^{2}$ ), and who were undergoing laparoscopy were excluded, because these conditions are likely to affect postoperative respiratory function, such as ventilation-perfusion mismatch. ${ }^{13,14}$ Patients who experienced apnea, dyspnea, or arterial desaturation (defined as $\mathrm{S}_{\mathrm{pO}_{2}}<95 \%$ ) were also eliminated from the analysis. In the present study, we aimed to assess the accuracy of the measurements achieved by using the device. Therefore, we excluded patients who were considered at risk of postoperative respiratory dysfunction. Furthermore, the present study was implemented in the ICU; therefore, patients who were not admitted to the ICU were also excluded. The study period was $90 \mathrm{~min}$ for each subject.

\section{Study Protocol}

The capnometer was calibrated before oxygen administration. All subjects were extubated in the operating room, and oxygen was supplemented at $4 \mathrm{~L} /$ min during transfer to the ICU via a nasal cannula. The cannula was then replaced with a capnometry-type nasal cannula at the same oxygen flow. $\mathrm{P}_{\mathrm{ETCO}_{2}}$ was measured with a sidestream with the mouth closed and a capnometer via spectrophotometry.

\section{Measurements}

Arterial blood samples and $\mathrm{P}_{\mathrm{ETCO}_{2}}$ measurements were obtained 3 times, once every $30 \mathrm{~min}$. The breathing frequency was only measured with the mouth closed. $\mathrm{P}_{\mathrm{ETCO}_{2}}$ was measured arbitrarily during rest $\left(\mathrm{P}_{\mathrm{ETCO}_{2}}\right.$ at rest), during breathing with the mouth consciously closed $\left(\mathrm{P}_{\mathrm{ETCO}_{2}}\right.$ with mouth closed), and during deep breathing with mouth closed ( $\mathrm{P}_{\mathrm{ETCO}_{2}}$ with deep breathing). $\mathrm{P}_{\mathrm{ETCO}_{2}}$ was measured after a constant and normal-shaped capnography capnogram was confirmed at every 30 min of oxygen administration. $\mathrm{P}_{\mathrm{ETCO}}$ was measured with a sidestream monitor (Microstream, AG-400R, Nihon-Kohden, Tokyo, Japan). If the $\mathrm{P}_{\mathrm{ETCO}_{2}}$ was not detectable even with the nasal cannula appropriately fitted, the data point was recorded as such. All data measurements were collected by a critical care physician with training in respiratory monitoring and capnography.

\section{Data Analysis}

Quantitative variables are expressed as the median and interquartile range. The correlation between the breathing frequency by direct measurement and the breathing frequency measured with the capnometer while breathing with the mouth consciously closed was analyzed using the Pearson product-moment correlation coefficient for assessing validity and reliability.

Each variable was measured several times in each subject, and the mean bias, precision, and limits of agreement were estimated by the component of variance technique. ${ }^{15}$ The bias, precision, and limits of agreement between the $\mathrm{P}_{\mathrm{aCO}_{2}}$ and $\mathrm{P}_{\mathrm{ETCO}_{2}}$ at rest, $\mathrm{P}_{\mathrm{ETCO}}$ with mouth closed, and $\mathrm{P}_{\mathrm{ETCO}_{2}}$ with deep breathing were calculated using the BlandAltman method. The differences between $\mathrm{P}_{\mathrm{ETCO}_{2}}$ and $\mathrm{P}_{\mathrm{aCO}_{2}}$ under various breathing conditions were analyzed with one-way analysis of variance. All tests were 2-tailed, and $P<.05$ was considered statistically significant. The statistical analyses were performed using Prism 6 for Mac OS X version 6.9b (GraphPad Software, San Diego, California).

The sample size was calculated based on a power analysis performed using $G^{*}$ power software. The $G^{*}$ power analysis indicated that 17 subjects were required for a 2 -sided test with a significance of .05 , power of 0.8 , and estimated coefficient of determination $\left(\mathrm{r}^{2}\right)$ of 0.36 . Therefore, 23 subjects were enrolled in the present study. 


\section{Nasal Cannula-Based Capnometry in Extubated Subjects}

Table 1. Clinical and Perioperative Subject Characteristics

\begin{tabular}{lc}
\hline \hline \multicolumn{1}{c}{ Characteristics } & \multicolumn{1}{c}{ Values } \\
\hline Male sex, $n(\%)$ & $13(65)$ \\
Age, median (IQR) y & $66(61-72)$ \\
Weight, median (IQR) kg & $61.5(52.0-68.7)$ \\
BMI, median (IQR) kg/m ${ }^{2}$ & $22.9(20-24)$ \\
Smoker, $n(\%)$ & $7(35)$ \\
Total fentanyl dosage, median (IQR) $\mu \mathrm{g}$ & $650(462.5-1000)$ \\
Anesthesia duration, median (IQR) $\mathrm{h}$ & $11.9(10.7-12.6)$ \\
Fluid administration intraoperatively, & $4204(3121-4537)$ \\
$\quad$ median (IQR) mL & \\
\hline$N=20$. & \\
IQR $=$ interquartile range & \\
BMI $=$ body mass index &
\end{tabular}

\section{Results}

Twenty-three subjects were enrolled, of whom 3 subjects were excluded due to insufficient data collection. The remaining 20 subjects ( 13 men, 7 women), with a median age of 66 y (interquartile range, 61-72 y) and body mass index of $20-24 \mathrm{~kg} / \mathrm{m}^{2}$, were included in the analysis (Table 1). All subjects tolerated the capnometry-type nasal cannula, and the $\mathrm{S}_{\mathrm{pO}_{2}}$ remained $>95 \%$ during oxygen supplementation. The capnogram and $\mathrm{P}_{\mathrm{ETCO}_{2}}$ at rest were not detectable in 3 subjects ( 3 of 20,15\%). A normal-shaped capnogram was displayed during closed mouth breathing in all subjects.

The breathing frequencies during breathing with the mouth consciously closed measured by capnometry and directly measurement were significantly correlated $\left(P<.001 ; \mathrm{r}=0.66[0.48-0.78] ; \mathrm{r}^{2}=0.43\right)$. The BlandAltman analysis showed that the bias \pm SD (limits of agreement) between the breathing frequency with the 2 different measurement approaches was $0.4 \pm 3.6(-6.7$ to 7.4) (Fig. 2).

The Bland-Altman analyses revealed that the biases \pm SD (limits of agreement) between $\mathrm{PaCO}_{2}$ and either $\mathrm{P}_{\mathrm{ETCO}_{2}}$ at rest, $\mathrm{P}_{\mathrm{ETCO}_{2}}$ with mouth closed, and $\mathrm{P}_{\mathrm{ETCO}_{2}}$ with deep breathing were $14.8 \pm 8.2(-1.3$ to 30.9$), 10.2 \pm 6.4$ ( -2.3 to 22.7$)$, and $7.7 \pm 5.6$ ( -3.2 to 18.6$)$, respectively (Fig. 3). The difference between $\mathrm{P}_{\mathrm{aCO}}$ and $\mathrm{P}_{\mathrm{ETCO}}$ was significantly smaller during deep breathing with the mouth closed than at rest, with or without the mouth closed $(P<.001$, one-way analysis of variance $)$.

\section{Discussion}

In the present study, we evaluated an oxygen nasal cannula-based capnometry device in terms of $\mathrm{P}_{\mathrm{ETCO}_{2}}$ and breathing frequency monitoring in extubated subjects after abdominal surgery. Moreover, $\mathrm{P}_{\mathrm{ETCO}_{2}}$ was measured un-

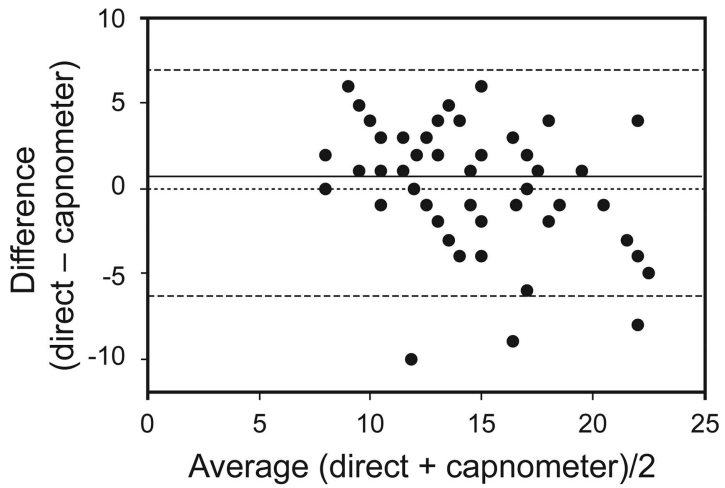

Fig. 2. Bland-Altman plot of breathing frequency between direct and capnometer measurements using the nasal cannula. The bias \pm $\mathrm{SD}$ (limits of agreement) between the breathing frequency with the 2 different measurement approaches was $0.4 \pm 3.6$ (-6.7 to 7.4).

der various breathing patterns. The capnography capnogram was not detectable in 3 of 20 subjects when they were breathing in the resting condition, whereas we could observe the capnogram in all subjects when we asked them to breathe with their mouths closed.

In the present study subjects, appropriate pain control could support deep breathing with a consciously closed mouth. As expected, rapid shallow breathing due to pain and respiratory dysfunction was not detected in any of the subjects. This suggests that some postoperative subjects are breathing mainly through the mouth and have respiratory difficulties due to insufficient pain control which poses an obvious and significant problem when we use this device clinically.

This is also in contrast to the capnometry-type face mask that we investigated previously, ${ }^{11}$ because the $\mathrm{P}_{\mathrm{ETCO}_{2}}$ could be monitored in all subjects, regardless of whether the mouth was open or closed. Moreover, we also found that the breathing frequencies measured directly and by the nasal cannula correlated well $(r=0.66)$ when the subjects were breathing with their mouths closed. Moreover, the Bland-Altman method showed that the difference (ie, bias) \pm SD (limits of agreement) of the breathing frequency between 2 different measurement was $0.4 \pm 3.6$ $(-6.7$ to 7.4$)$. The reason for the discrepancy in breathing frequency as measured by capnometry and measured directly may be that expiratory flow was intermittently discontinued, resulting in a double count upon capnography. Furthermore, the breathing frequency measured by capnometry is not counted for $1 \mathrm{~min}$, but rather calculated by the length of expiration, breath by breath. This method of calculation may hence be affected by differences in the breathing frequency between capnography and direct measurement. In the present study, the breathing frequency was measured once for each measurement at arbitrary time points. Usage of the mean breathing frequency by repeated measurements for 1 min might improve the correlation of 

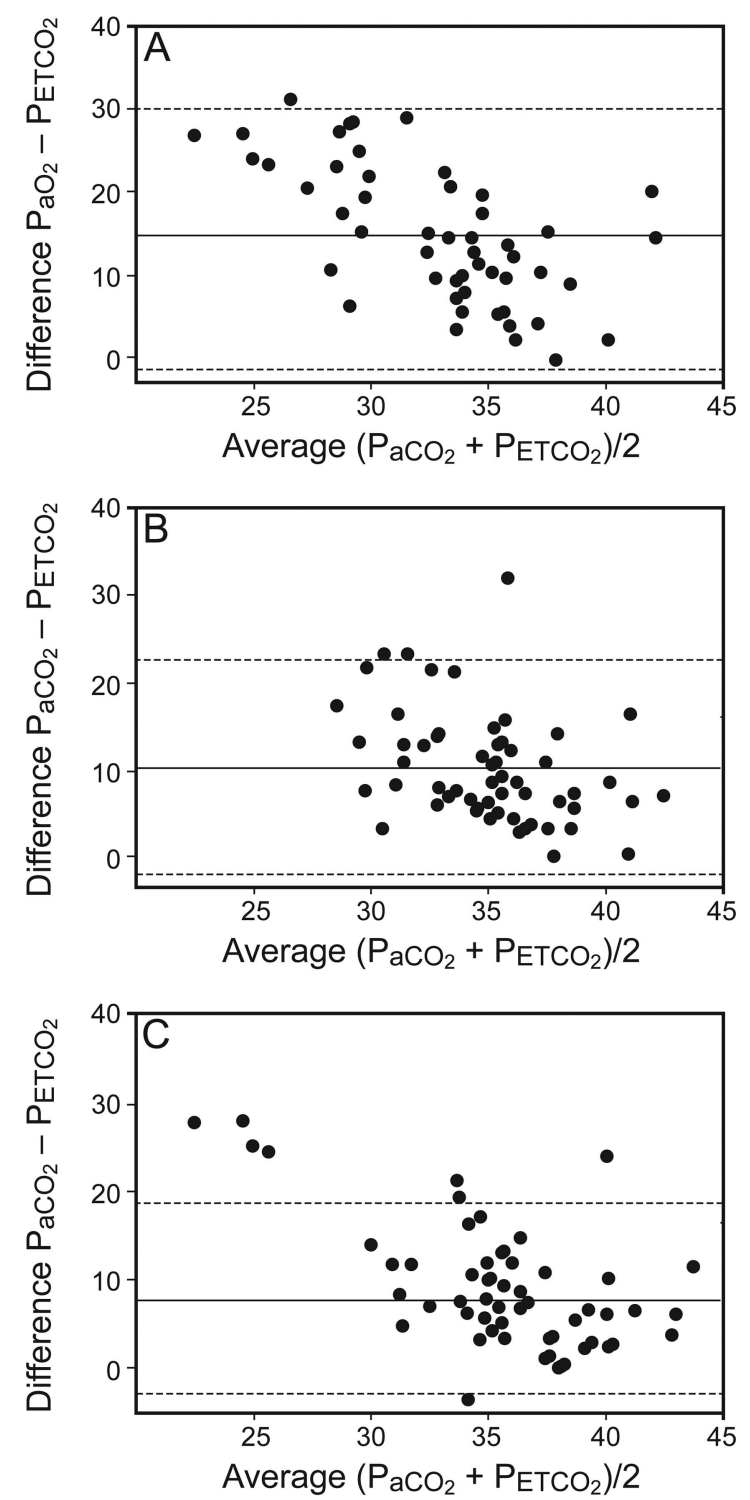

Fig. 3. Bland-Altman analysis of the end-tidal carbon dioxide concentration $\left(\mathrm{P}_{\mathrm{ETCO}}\right)$ during resting $(A)$, with mouth closed $(B)$, and during deep breathing $(C)$ while administering oxygen supplementation at $4 \mathrm{~L} / \mathrm{min}$. The biases $\pm \mathrm{SD}$ (limits of agreement) were $14.8 \pm 8.2(-1.3$ to 30.9$)$ for $\mathrm{P}_{\mathrm{ETCO}}$ during resting, $10.2 \pm 6.4$ (-2.3 to 22.7) for $\mathrm{P}_{\mathrm{ETCO}}$ with mouth closed, and $7.7 \pm 5.6(-3.2$ to 18.6) for $\mathrm{P}_{\mathrm{ETCO}}$ during deep breathing.

breathing frequency between the 2 methods. Although the value of breathing frequency with the capnogram is unreliable, the oxygen nasal cannula-based capnometry device may help detect hypoventilation under continuous measurement.

In addition, we also compared the $\mathrm{P}_{\mathrm{ETCO}_{2}}$ and $\mathrm{P}_{\mathrm{aCO}_{2}}$ under various breathing conditions and found that the differences (biases) were 14.8, 10.2, and $7.7 \mathrm{~mm} \mathrm{Hg}$ during resting breathing, mouth closed breathing, and deep breathing, respectively. These values appear somewhat greater than the reported differences between $\mathrm{P}_{\mathrm{ETCO}_{2}}$ and $\mathrm{P}_{\mathrm{aCO}_{2}}$ in intubated subjects, which average $5 \mathrm{~mm} \mathrm{Hg}$ but can be as high as $15 \mathrm{~mm} \mathrm{Hg.}{ }^{16,17}$ However, they compare favorably with those measured with the previously investigated oxygen mask-based capnometry, ${ }^{11}$ for which we reported that the differences were 12.6 and $9.1 \mathrm{~mm} \mathrm{Hg}$ during resting breathing (regardless of the mouth condition) and deep breathing, respectively.

Interestingly, the difference between the $\mathrm{P}_{\mathrm{aCO}}$ and $\mathrm{P}_{\mathrm{ETCO}_{2}}$ gradually decreased from resting breathing to mouth closed breathing to deep breathing. The difference depends mainly on 3 factors: the dead space (defined as the tidal volume component that does not participate in gas exchange), ventilation/perfusion matching, and the amount of exhaled breath available for sampling. The reason for the greater difference during resting breathing than during the mouth closed condition may be explained by the amount of exhaled breath available for sampling. It is possible that variable fractions of the tidal volume were exhaled through the mouth during the resting condition, leaving an insufficient amount for sampling through the nasal cannula $\mathrm{CO}_{2}-$ monitoring port. In this case, the sampled gas may be contaminated by the supplied oxygen and ambient air, and the $\mathrm{P}_{\mathrm{ETCO}_{2}}$ would be lower. The reasons for the smaller difference between the $\mathrm{P}_{\mathrm{ETCO}_{2}}$ and $\mathrm{P}_{\mathrm{aCO}}$ during deep breathing when compared with mouth closed breathing may include all 3 of these factors. Even when the mouth is closed and the entire tidal volume is exhaled through the nose, some breaths might be too small to prevent contamination by the ambient air during resting breathing. However, this was less likely during deep breathing, because deep breathing increase the inspiratory and expiratory flow rate, which decrease contamination by the ambient air. More importantly, the difference between $\mathrm{P}_{\mathrm{ETCO}_{2}}$ and $\mathrm{P}_{\mathrm{aCO}_{2}}$ is heavily dependent on the ratio of the dead space to the tidal volume. Obviously, the tidal volume during deep breathing is greater than that during resting breathing, whereas the dead space remains relatively unchanged. Therefore, it is not surprising that the difference between the $\mathrm{P}_{\mathrm{ETCO}_{2}}$ and $\mathrm{P}_{\mathrm{aCO}_{2}}$ was the smallest during deep breathing.

Our results suggest that it may be difficult to predict the $\mathrm{P}_{\mathrm{aCO}_{2}}$ from the $\mathrm{P}_{\mathrm{ETCO}_{2}}$ due to the wide limits of agreement between the $\mathrm{P}_{\mathrm{aCO}_{2}}$ and $\mathrm{P}_{\mathrm{ETCO}}$, irrespective of the breathing pattern $(32 \mathrm{~mm} \mathrm{Hg}$ [resting] vs $23 \mathrm{~mm} \mathrm{Hg}$ [with mouth closed] vs $22 \mathrm{~mm} \mathrm{Hg}$ [deep breathing]). This is despite the fact that we studied a relatively homogeneous population of subjects (ie, open abdominal surgery, presence of epidural anesthesia, exclusion of obesity). The lung mechanics change following abdominal and thoracic surgery. ${ }^{18}$ After upper abdominal surgery, the vital capacity is typically reduced to $\sim 40 \%$ of its baseline value and remains depressed for at least 10-14 d. The functional residual capacity is also decreased to $\sim 70 \%$ for several days, before gradually improving to a normal level by 1 week postoperatively. ${ }^{18}$ These changes in respiratory function 


\section{Nasal Cannula-Based Capnometry in Extubated Subjects}

affect the dead space and are the likely cause of the wide range of differences between $\mathrm{P}_{\mathrm{ETCO}_{2}}$ and $\mathrm{P}_{\mathrm{aCO}}$. Another potential reason for the wide range of differences between $\mathrm{P}_{\mathrm{ETCO}_{2}}$ and $\mathrm{P}_{\mathrm{aCO}}$ is the effect of contamination of the oxygen flow and dilution of the $\mathrm{CO}_{2}$ value. Paul and colleagues et $\mathrm{al}^{19}$ reported a significant inverse linear relationship between $\mathrm{P}_{\mathrm{ETCO}_{2}}$ and the oxygen flow. Even at a low oxygen flow, supplied at $4 \mathrm{~L} / \mathrm{min}$, contamination between the expired respiratory gases and oxygen flow might affect the $\mathrm{P}_{\mathrm{ETCO}_{2}}$ value. Further research will be required in other critical care populations, with various pain, sedative, and supplied oxygen levels, to compare our results with those obtained using other capnometry devices.

Finally, in the present study, it should be noted that we mainly discussed the accuracy of the $\mathrm{P}_{\mathrm{ETCO}_{2}}$ value, because the use of absolute values of breathing frequency and $\mathrm{P}_{\mathrm{ETCO}_{2}}$ may be difficult for detecting hypoventilation in the post-anesthesia care unit because of poor accuracy. Moreover, these evaluations of breathing frequency and $\mathrm{P}_{\mathrm{ETCO}_{2}}$ with various breathing patterns require bedside staff for measurements. Therefore, this device may not be useful for routine respiratory monitoring in the postoperative care unit. However, breathing patterns, such as deep breathing with the mouth closed, improved detection of the absolute value of $\mathrm{P}_{\mathrm{ETCO}}$.

This study has several limitations. First, the sample size was small, with only 20 subjects, and none of the enrolled subjects had a respiratory comorbidity or anthropometric condition, such as obesity. Second, the subject population was limited to those undergoing abdominal surgery, and the monitoring device was a nasal cannula with sidestream; therefore, the results may not be applicable to other surgical populations and other monitoring devices, such as the nasal/oral sampling technique. Third, the data collection was not blinded. Potentially, the physician in charge may have predicted that the $\mathrm{P}_{\mathrm{ETCO}_{2}}$ would increase following deep breathing, which may have biased the results.

\section{Conclusions}

Closing the mouth and deep breathing may help decrease the difference between $\mathrm{P}_{\mathrm{ETCO}_{2}}$ and $\mathrm{P}_{\mathrm{aCO}}$, thereby enabling more accurate prediction of the absolute $\mathrm{P}_{\mathrm{aCO}}$ value. Although the capnometry-type oxygen cannula device may not be useful for continuous respiratory monitoring due to unstable measurement, $\mathrm{P}_{\mathrm{ETCO}_{2}}$ measurements under deep breathing with the mouth closed with a capnometry-type oxygen cannula improve the prediction of the absolute value of $\mathrm{P}_{\mathrm{aCO}}$ in extubated post-abdominal surgical subjects without respiratory dysfunction.

\section{ACKNOWLEDGMENTS}

We thank Editage for English language editing.

\section{REFERENCES}

1. American Society of Anesthesiologists Task Force on Postanesthetic Care. Practice guidelines for postanesthetic care: a report by the American Society of Anesthesiologists Task Force on Postanesthetic Care. Anesthesiology 2002;96(3):742-752.

2. Apfelbaum JL, Silverstein JH, Chung FF, Connis RT, Fillmore RB, Hunt SE, et al. Practice guidelines for postanesthetic care: an updated report by the American Society of Anesthesiologists Task Force on Postanesthetic Care. Anesthesiology 2013;118(2):291-307.

3. Burton JH, Harrah JD, Germann CA, Dillon DC. Does end-tidal carbon dioxide monitoring detect respiratory events prior to current sedation monitoring practices? Acad Emerg Med 2006;13(5):500504.

4. Keidan I, Gravenstein D, Berkenstadt H, Ziv A, Shavit I, Sidi A. Supplemental oxygen compromises the use of pulse oximetry for detection of apnea and hypoventilation during sedation in simulated pediatric patients. Pediatrics 2008;122(2):293-298.

5. Fu ES, Downs JB, Schweiger JW, Miguel RV, Smith RA. Supplemental oxygen impairs detection of hypoventilation by pulse oximetry. Chest 2004;126(5):1552-1558.

6. Soto RG, Fu ES, Vila H Jr, Miguel RV. Capnography accurately detects apnea during monitored anesthesia care. Anesth Analg 2004; 99(2):379-382, table of contents.

7. Block FE Jr., McDonald JS. Sidestream versus mainstream carbon dioxide analyzers. J Clin Monit 1992;8(2):139-141.

8. Pascucci RC, Schena JA, Thompson JE. Comparison of a sidestream and mainstream capnometer in infants. Crit Care Med 1989;17(6): 560-562.

9. Chan KL, Chan MT, Gin T. Mainstream vs. sidestream capnometry for prediction of arterial carbon dioxide tension during supine craniotomy. Anaesthesia 2003;58(2):149-155.

10. Kasuya Y, Akça O, Sessler DI, Ozaki M, Komatsu R. Accuracy of postoperative end-tidal $\mathrm{P}_{\mathrm{CO}_{2}}$ measurements with mainstream and sidestream with mouth closed apnography in non-obese patients and in obese patients with and without obstructive sleep apnea. Anesthesiology 2009;111(3):609-615.

11. Takaki S, Mihara T, Mizutani K, Yamaguchi O, Goto T. An evaluation of an oxygen mask-based capnometry device in subjects extubated after abdominal surgery. Respir Care 2015;60(5):705-710.

12. Brown ES, Johnson RP, Clements JA. Pulmonary surface tension. J Appl Physiol 1959;14:717-720.

13. Warner DO. Preventing postoperative pulmonary complications: the role of the anesthesiologist. Anesthesiology 2000;92(5):1467-1472.

14. Griffin J, Terry BE, Burton RK, Ray TL, Keller BP, Landrum AL, et al. Comparison of end-tidal and transcutaneous measures of carbon dioxide during general anaesthesia in severely obese adults. Br J Anaesth 2003;91(4):498-501.

15. Bland JM, Altman DG. Measuring agreement in method comparison studies. Stat Methods Med Res 1999;8(2):135-160.

16. Nunn JF, Hill DW. Respiratory dead space and arterial to end-tidal carbon dioxide tension difference in anesthetized man. J Appl Physiol 1960;15:383-389.

17. Pansard JL, Cholley B, Devilliers C, Clergue F, Viars P. Variation in arterial to end-tidal $\mathrm{CO}_{2}$, tension differences during anesthesia in the "kidney rest" lateral decubitus position. Anesth Analg 1992;75(4): 506-510.

18. Craig DB. Postoperative recovery of pulmonary function. Anesth Analg 1981;60(1):46-52.

19. Paul J, Ling E, Hajgato J, McDonald L. Both the OxyArm and Capnoxygen mask provide clinically useful capnographic monitoring capability in volunteers. Can J Anesth 2003;50(2):137-142. 